\title{
Collaborative research as boundary work: learning between rice growers and conservation professionals to support habitat conservation on private lands
}

\author{
Erin Hardie Hale ${ }^{1} \cdot$ Christopher C. Jadallah $^{2}$ (D $\cdot$ Heidi L. Ballard ${ }^{2}$
}

Accepted: 3 November 2021 / Published online: 1 December 2021

(c) The Author(s) 2021

\begin{abstract}
Multi-stakeholder initiatives for biodiversity conservation on working landscapes often necessitate strategies to facilitate learning in order to foster successful collaboration. To investigate the learning processes that both undergird and result from collaborative efforts, this case study employs the concept of boundary work as a lens to examine learning between rice growers and conservation professionals in California's Central Valley, who were engaged in a collaborative research project focused on migratory bird conservation. Through analysis of workshop observations, project documents, and interviews with rice growers and conservation professionals, we identified five distinct factors of the collaborative research process that influenced learning amongst these two groups: having mutually beneficial goals, sharing ownership of the collaborative research process, building trust, integrating knowledge, and institutional alignment. We also examined and identified learning outcomes for both rice growers and conservation professionals, which included new knowledge of the social-ecological system, new practices around farming and collaboration, and shifting identities. Our findings suggest that applying these factors and outcomes for learning when structuring collaborative research, and other multi-stakeholder initiatives, can foster learning amongst diverse stakeholder groups to support new approaches for balancing resource use and adaptive management.
\end{abstract}

Keywords Collaborative research $\cdot$ Boundary work $\cdot$ Learning $\cdot$ Biodiversity

\section{Abbreviations \\ MBCP Migratory Bird Conservation Partnership \\ CRC California Rice Commission \\ NRCS Natural Resource Conservation Service}

\section{Introduction}

Rangelands, forests, and cultivated lands, collectively occupying $~ 80 \%$ of Earth's terrestrial area, offer high potential for conservation given that protected areas alone will not be sufficient in meeting goals to conserve biodiversity (Kremen and Merenlender 2018). Conservation in working landscapes and on private lands is thus critical to maintaining and conserving biodiversity and wildlife habitat across the globe (Polasky et al. 2005). Although some land uses are clearly incompatible with conservation goals, many species can tolerate some degree of disturbance and landscape alteration more than previously recognized (Richter and Redford 1999; Polasky et al. 2005; Kremen and Merenlender 2018). Thus, there is a growing recognition within the conservation community that ecosystems must be managed collaboratively to include protected areas as well as economically productive and privately owned agricultural, pastured, and forested landscapes (Theobald and Hobbs 2002; Knight et al. 2010; Raymond and Brown 2011), and that this requires the different but complementary knowledge, skills and values of ecologists and land managers (Daniels and Walker 
2001). Collaborative approaches often emphasize adaptive management whereby stakeholders learn by experimenting with various management practices and modify approaches based on the results and feedback from these experiments and the experiences of the land managers involved (Lee 1993; Armitage et al. 2007). In an adaptive, collaborative approach, the focus is on learning and continued change and experimentation to address the complexity, dynamism, and non-linearity of social-ecological systems (Pahl-Wostl and Hare 2004; Folke et al. 2005; Armitage et al. 2008). This is a key principle for reconciling agriculture and conservation (Sayer et al. 2013).

Considerable consensus has emerged that learning is a normative goal in environmental management and conservation (Pahl-Wostl and Hare 2004; Armitage et al. 2008; Gerlak et al. 2019). However, there is a lack of clarity and specificity with respect to the goals, approaches, and outcomes of learning as individuals and groups seek to collaboratively understand, manage, and identify strategies to deal with environmental change (Folke et al. 2005; Berkes and Turner 2006; Gerlak et al. 2018). This paper explores a unique collaborative research project involving rice growers and conservation professionals in California's Sacramento Valley, to examine ways in which they learned with and from each other about how to enhance habitat for migratory birds without compromising the viability of their agricultural operations. The goal of the study was to examine how the conservation and rice grower groups in this case learned together about developing new land management practices and what the outcomes of the learning process were for individuals, communities, and ecosystems. Specifically, we employ the concept of boundary work between different communities, to be defined subsequently, as a guiding analytical lens for identifying the factors that support learning, and ultimately, conservation action in the context of collaborative agroecosystem management.

\section{Literature review}

Increasingly, scholars have identified learning amongst stakeholders as a paramount consideration and key mechanism for achieving positive conservation outcomes in that it can build adaptive capacity and support the integration of diverse perspectives (Armitage et al. 2008; Berkes 2009; Fernández-Giménez et al. 2019). Various terms such as social learning, policy learning, and organizational learning have been employed in empirical research to describe how and what people learn in the unique context of conservation and natural resource management (Gerlak et al. 2018). Research in these fields has examined how interaction, communication, and collaboration between stakeholders leads to both individual and collective learning in these contexts (Gerlak et al. 2018; Muro and Jeffrey 2008; Rodela 2013).

We build on this research by drawing specifically on sociocultural theories of learning to better understand the learning processes and outcomes that occur in the context of collaborative scientific research focused on conservation in working landscapes. Sociocultural theories of learning emphasize that cognition and meaning are socially and culturally constructed in the sense that learning occurs through participation in meaningful social activity (Wenger 1998; Lemke 2001). Central to this idea is that a person's understanding and ability to perform activities develop as a consequence of participating in shared activity (Lave and Wenger 1991; Wenger 1998). Knowing, from this perspective, is not an accumulated body of knowledge, facts, or content but is focused on "belonging, participating, or the ability to master new knowledge and tasks while participating in social practice" (Lave and Wenger 1991, p. 52). Learning can happen at the individual level, as participants develop new skills, abilities, and identities by moving from peripheral to full forms of participation, and at the community level, in that the practice itself is maintained, adapted, and negotiated over time (Wenger 1998). While the distinct communities participating in collaborative research initiatives like the Rice and Birds project (e.g., rice growers and conservation professionals) might be conceptualized as communities of practice as first described by Lave and Wenger's (1991) theory of situated learning, our goal is not to establish whether the groups participating in the Rice and Birds project meet the formal criteria of this construct. Rather, we draw on the concepts of boundaries and boundary work from their theory to understand the factors that influence how and what rice growers and conservation professionals learn when participating in collaborative research.

According to Wenger (2010), learning and collaboration between communities often happens across boundaries, at the edges of practice where new ideas and skills are introduced and tested. Important in the context of this paper, just as learning can be influenced by the ways individuals within a community collaborate and exchange knowledge while engaging in shared practice, different communities have distinct repertoires of practice and can also learn from each other across boundaries as well. While boundaries can be vital forces for change and development by serving as ambiguous, yet productive sites for learning (Star 2010; Akkerman and Bakker 2011), they can also be obstacles for learning by preventing communication and collaboration between communities (Gieryn 1983; Lamont and Molnár 2002). In our case, the relevant distinction is boundaries between scientist and farmer communities about what constitutes reliable knowledge (Cash et al. 2003; Clark et al. 2011). Essentially, tensions may arise between scientists and decision-makers, or in this case, conservation professionals 
conducting research and rice growers managing land, who have different views about what constitutes reliable knowledge. The boundaries that emerge can prevent meaningful communication between these communities and thus inhibit the translation and implementation of research-based action and decision-making (Lamont and Molnár 2002; Armitage et al. 2007; Berkes 2009).

The term boundary work has been defined as the "acts and structures that create, maintain, and break down boundaries" involving "the processes whereby legitimacy and cognitive authority are attached to knowledge" (Fisher 1989, p. 162). Numerous studies have employed the concepts of boundary work and boundary objects (artifacts that help to bridge intersecting practices) to examine processes and structures that facilitate or hinder the co-management of natural resources (Clark et al. 2011; Zurba and Berkes 2014; Zurba et al. 2019). According to Zurba et al. (2019), community-based and participatory research methodologies in co-management contexts can be considered boundary work, as they support co-creation and knowledge sharing between research partners and help to translate research outcomes into action. While the enterprise of participatory, collaborative research has a history of both documented successes and failures, there has been little examination of the processes and dynamics that contribute to successful participatory research approaches and learning in the context of wildlife conservation in privately owned, agricultural landscapes (Cerf et al. 2000; Leeuwis and Pyburn 2002; Pretty and Smith 2004). Nevertheless, research on participation and boundary work in other agricultural and natural resource contexts offer valuable insights into the factors that facilitate learning across community boundaries in collaborative research settings.

One such example includes the review of boundary work practices across the Consultative Group on International Agricultural Research Alternatives to Slash and Burn programs that facilitated a shift from a one-directional, extension model of technology transfer towards a bi-directional, collaborative farming systems research model (Clark et al. 2011). The review discusses the shortcomings of the expert or one-directional model of research and its failure to integrate farmers' and researchers' knowledge, generally defining agendas in terms of researchers' solutions rather than farmers' problems. This shift in research models involved significant boundary work that included factors we identified in the Rice and Birds project and have been recognized by researchers in other contexts as well, such as: mutually beneficial goals (Robinson and Wallingford 2012); shared ownership of process (Muro and Jeffrey 2008; Reed 2008; Ballard and Belsky 2010; Robinson and Wallingford 2012; Zurba et al. 2019); building trust and relationships between farmers and researchers (FernándezGiménez et al. 2008; Wagner and Fernández-Giménez 2008; Ernst 2019) and integrating knowledge between the farmer and scientist communities through participatory research and management methodologies (Cash et al. 2003; Berkes et al. 2000; Ballard et al. 2008). Similar to Clark et al (2011)'s notion of accountability as an important factor in successful boundary work, others have noted the importance of linkages with institutions and networks at different scales beyond the immediate research participants to ensure that what is learned gets shared and disseminated across communities and not just among those involved in the boundary practice (Wenger 1998; Akkerman and Bakker 2011; Robinson and Wallingford, 2012; Zurba et al. 2019).

Building on the literature reviewed above, we examine the factors that facilitated or hindered learning and collaboration at the boundaries between the grower and conservation communities in the context of the collaborative Rice and Birds research project. We also identify the learning outcomes for rice growers and conservation professionals from this collaborative process. We define these learning outcomes across boundaries according to Wenger's (1998) definition of learning as participation in social practice, including: new knowledge and understanding about a given practice (in this case, understanding how to manage rice fields for migratory bird habitat); new practices (the development of new field management practices); and shifting identities (changes in competence, roles, and membership within and between communities). Given that the collaborative project in 2010-2011 was the catalyst for successful and ongoing partnerships that continue to grow, a close examination of these early efforts provides lessons for future projects focused on wildlife conservation in privately-owned, agricultural landscapes.

\section{Methods}

\section{Case study context}

The Rice and Birds project provides an important case of a collaborative effort to identify, implement and evaluate field management practices that enhance the habitat value of agricultural lands, in this case between rice growers and conservation professionals. The effort began when the Migratory Bird Conservation Partnership (MBCP), a collection of scientists and managers from Audubon California, The Nature Conservancy, and Point Blue Conservation Science (at the time known as PRBO Conservation Science), along with rice growers in the Sacramento Valley involved with the California Rice Commission (CRC), met in 2009 to discuss ways to modify rice management practices to benefit migratory shorebirds. Those initial conversations led to 10 growers and farm managers agreeing to participate in a process of adaptive experimentation (Berkes et al. 2009) during the 2010-2011 growing season, whereby they would implement, monitor, and evaluate 
Table 1 Boundary encounters between growers and conservation professionals

Formally organized encounters

- Winter 2009 kickoff workshop

- Winter 2010 reflective workshop

- One-on-one meetings between farmers and conservation professionals
Informal encounters

- Phone calls before monitoring site visits

- Conversations during monitoring site visits those practices on their farms in partnership with conservation professionals.

This collaborative effort can be further situated with the context of significant land use change in California's Central Valley, where more than $95 \%$ of historic wetlands and $98 \%$ of all riparian habitats have been destroyed or modified over the last 150 years (Audubon 2012). Despite these changes, the Central Valley remains a critical habitat for waterfowl, as well as important habitat for resident and migratory shorebirds, raptors, songbirds, and many other species. It is estimated that 70 percent of the food needed to support the more than 5 million waterfowl wintering in the Central Valley every year is produced by private agricultural land (Audubon 2012). In addition, thousands of acres of harvested rice fields are intentionally flooded during fall, winter, and spring to encourage decomposition of rice straw, providing habitat that has valuable potential as a means to recreate some of California's lost wetlands (Elphick and Oring 1998; Elphick 2000). Determining how best to simulate true wetland habitat in flooded rice fields, and thereby protect and restore critical habitats for migratory birds in California, has become an important avenue of research within the bird conservation community (Elphick 2000). In the specific Rice and Birds case, the interactions between the rice growers and conservation professionals provided a context of both formal and informal boundary encounters (Cash et al. 2003; Clark et al. 2011), offering a space for conservation professionals and rice growers to engage in shared practice and learn from each other (Table 1).

These efforts have grown considerably since the initial 2010-2011 adaptive experimentation process. Programs such as the Natural Resource Conservation Service (NRCS) Waterbird Habitat Enhancement Program and the Nature Conservancy's BirdReturns, for example, provide economic incentives to rice growers for implementing bird-friendly practices in their fields. In the specific case of BirdReturns, conservation professionals have documented more than 1.8 million birds on the fields of BirdReturns participants since 2014 (California Ricelands Waterbird Foundation 2018), with over 100 farmers participating to create 58,000 acres of short-term habitat for shorebirds (BirdReturns 2020).

Notably, these expansions were built on the foundations of the earlier collaborative effort during the 2010-2011 growing season. How did these communities, organizations, and individuals involved in the earlier Rice and Birds project come to trust each other in a way that supported these much larger efforts? We suggest that examining the earlier small collaborative program that catalyzed these later successes, and the learning that happened as part of them, can help us better understand mechanisms by which collaborative research can be a tool for biodiversity conservation on working landscapes. To accomplish this, we draw from and analyze interviews, workshop observations, documents, and artifacts produced as part of this initial effort of adaptive experimentation and collaborative research and collected between 2010 and 2011. We identified the moments in which conservational professionals and rice growers engaged in boundary work and examined and identified learning outcomes for both rice growers and conservation professionals, which included new knowledge of the social-ecological system, new practices around farming and collaboration, and shifting identities. All participants provided their consent to participate in this study, and pseudonyms are used when referring to the names of specific individuals.

\section{Data collection}

\section{Interviews}

We interviewed 8 out of 10 rice growers participating actively in field research, as identified by the leaders from the growers' organization and the MBCP, as well as 8 conservation professionals directly involved with the collaboration. We use the term conservation professional to encompass both scientists and project managers, who do both research and management in their work. The interviews were semi-structured and employed open-ended questions (Weiss 1995), which were designed to yield in-depth responses about topics such as biographical information, knowledge of local agricultural practices and local ecology, conservation philosophy, agricultural practices, and perceptions of and experiences with the collaborative research and development process.

\section{Workshop observations}

We collected ethnographic fieldnotes and audio-recorded and transcribed dialogue from one five-hour reflective workshop in 2010 between rice growers and conservation 
professionals. This workshop was focused on discussion of the results of the first year of bird responses to the pilot field management techniques and had the goal of engaging growers in dialogue about refining and brainstorming new management practices to test. The workshop was attended by 30 rice growers, including the 8 that were interviewed, and approximately 10 conservation professionals, and was facilitated by an outside, hired consultant, and organized jointly by the MBCP and CRC.

\section{Documents and artifacts}

We collected internal organizational documents about the origin and organization of the project, publicly available workshop proceedings, workshop presentations, and other artifacts produced by core organizations such as websites, articles, pamphlets, etc. This allowed us to better understand the history of the project as well as the ways in which participants and organizations portrayed themselves to external audiences (Merriam 1998).

\section{Data analysis}

To analyze our data, we qualitatively coded the interviews, workshop fieldnotes and transcripts, and secondary documents and artifacts, both deductively and inductively, using themes identified in the literature described above as well as themes that emerged from the data themselves. Using the constant comparative method (Glaser and Strauss 1967), we generated a large list of codes to describe patterns found in the literature. Using this iterative method, we constantly compared, refined, narrowed and re-coded data as each data source was analyzed to arrive at our findings for each theme. We identified several key themes used to thematically code the different data sources (Table 2).
We attempted to address issues of internal validity, or the extent to which our interpretations matched reality (Merriam 1998), by having participants (including MBCP scientists and grower representatives) involved in all phases of the research process, specifically in developing the interview questions, suggesting, and facilitating interview participants, and reviewing and commenting on the (anonymized) findings as they emerged. This served as a form of member checking to ensure that our interpretations of the learning processes using the above key themes were in accordance with the participants' own ascribed meanings to said processes.

\section{Results and discussion}

\section{Factors that support learning across boundaries}

While planned and spontaneous boundary encounters are an important precursor to learning across the communities, simply participating in a boundary encounter is no guarantee that learning will occur, unless it is a productive space for dialogue, perspective sharing, and negotiation of meaning about the collaboration (Wenger 1998; Carr and Wilkinson 2005; Carr and Hazell 2006; Clark et al. 2011). Here we identify the factors that facilitated boundary crossing and learning across the two communities (Table 3). These included: mutually beneficial goals; shared ownership of process; building trust; integrating knowledge; and alignment with institutions and networks at other scales. These factors are emphasized in research on collaborative contexts (Wenger 1998; Johnson et al. 2003; Fernández-Giménez et al. 2008; Reed, 2008; Clark et al. 2011) and we found they also emerged as important themes in our interviews and workshop observations.

Table 2 Key themes for data analysis

\begin{tabular}{|c|c|c|}
\hline Theme & Definition & References \\
\hline Boundary encounters & $\begin{array}{l}\text { Interactions at the interface of distinct communities } \\
\text { (in this case, the rice grower community, and the } \\
\text { conservation professional community) }\end{array}$ & $\begin{array}{l}\text { Cash et al. (2003), Clark et al. (2011), and Wenger } \\
\text { (1998) }\end{array}$ \\
\hline Mutually beneficial goals & Shared desire to work together toward a common end & Clark et al. (2011), Zurba et al. (2019) \\
\hline Shared ownership of the process & $\begin{array}{l}\text { Joint decision-making and distributed sense of owner- } \\
\text { ship }\end{array}$ & $\begin{array}{l}\text { Ballard and Belsky (2010), Clark et al. (2011), Reed } \\
\text { (2008), and Zurba et al. (2019) }\end{array}$ \\
\hline Building trust & $\begin{array}{l}\text { Norms of reciprocity and improved relationships } \\
\text { amongst stakeholders }\end{array}$ & $\begin{array}{l}\text { Ernst (2019), Fernández-Giménez et al. (2008), and } \\
\text { Wagner and Fernández-Giménez (2008) }\end{array}$ \\
\hline Integrating knowledge & $\begin{array}{l}\text { Application of both local ecological knowledge and } \\
\text { conventional science in environmental problem- } \\
\text { solving }\end{array}$ & Berkes et al. (2000) and Ballard et al. (2008) \\
\hline Institutional alignment & $\begin{array}{l}\text { Linkages with institutions and networks at different } \\
\text { scales beyond the immediate participants }\end{array}$ & Akkerman and Bakker (2011) and Wenger (1998) \\
\hline
\end{tabular}


Table 3 Factors supporting learning across boundaries between rice growers and conservation professionals

\begin{tabular}{ll}
\hline Factors supporting learning & Evidence \\
\hline $\begin{array}{l}\text { Mutually beneficial goals } \\
\text { Shared ownership of process }\end{array}$ & $\begin{array}{c}\text { Both communities saw benefits in managing productive agricultural lands to promote habitat } \\
\text { The research process was jointly initiated by both communities, who continued to collaborate as the project } \\
\text { progressed. At times, however, rice growers' feedback and involvement were not prioritized }\end{array}$ \\
$\begin{array}{l}\text { Building trust } \\
\text { Integrating knowledge }\end{array}$ & $\begin{array}{l}\text { Having similar epistemological frameworks and skilled facilitators supported both communities in engaging in } \\
\text { boundary work and learning }\end{array}$ \\
Institutional alignment & $\begin{array}{c}\text { Linking their work with government agencies allowed for the collaborative research effort to grow and evolve in } \\
\text { relation to their practice }\end{array}$ \\
\hline
\end{tabular}

\section{Mutually beneficial goals}

We found that collaboration between growers and conservation groups in the Rice and Birds project arose not from conflict, as may often be the case in other natural resource management contexts, but from a shared desire to work together for some mutually beneficial goals. In fact, the ultimate goals of both communities were somewhat differentmost growers wanted to find a way to continue farming in a political and economic climate that makes it often difficult to do so, whereas the conservation groups were interested in protecting habitat for and boosting populations of migratory and resident birds. However, both groups found what they hoped to be a common means of reaching those goals: managing productive agricultural lands to promote bird habitat. Several participants, both growers and conservation professionals, described the relationship between rice growers and conservation groups as "symbiotic" during interviews, and described ways they recognized that the survival of agriculture in the Central Valley and of the birds who depend on the agricultural landscape were intimately linked. These references to symbiosis reveal one way that several participants felt they shared mutually beneficial goals with their collaborative partners.

We found this sense of shared vision relied on the commonly understood history of this landscape, specifically that rice fields already functioned as wetland habitat to many birds, an agroecological phenomenon that may not always be present for other natural resource contexts. When asked whether or not they agreed with the direction the rice community was moving in terms of aligning their interests with conservation goals, all of the rice growers interviewed agreed that it was a good strategy. Some, like Ron from Colusa, described the alliance as "natural:"

If I was a cotton grower, or even an almond grower, how am I going to align with them [environmental interests]? I can put my owl boxes up in the almond orchard but that doesn't cover the spectrum [of wildlife] that you find out in the rice areas.
This emphasizes the salience of the natural context: compared to other agricultural systems, rice fields already host abundant wildlife; discussions between growers and conservationists therefore focused on ways that current practices could be modified slightly to further enhance habitat while incurring minimal costs in terms of labor, infrastructure investment, and loss of production. At the same time, rice growers involved in this collaborative project made it clear during interviews and workshops that the collaboration wouldn't be perceived as mutually beneficial to the vast majority of growers unless there was a clear and immediate benefit to participation, in the form of incentive payments or market recognition of some kind. Their ability to see both perspectives simultaneously, the benefits of collaboration but the broader incentives needed for their colleagues, may have contributed to the successful identification of rice farming practices that promoted migratory bird habitat receiving NRCS approval and funding, and the establishment of BirdReturns in 2014.

\section{Shared ownership of process}

Shared decision-making and distributed sense of ownership in collaborative research settings is widely acknowledged to be a key factor of successful, truly participatory projects (Johnson et al. 2003; Danielsen et al. 2008; Reed 2008; Ballard and Belsky 2010; Clark et al. 2011). In this case, participants in both groups took credit for initiating the collaborative project, which is an excellent indicator of shared ownership. Conservation professionals reported in interviews that they initiated the process by contacting John B., the Environmental Affairs Director at the CRC; growers reported in interviews that John B. initiated contact with the conservation community. The reality, of course, was somewhere in between. According to Andy from Audubon,

To be honest, I can't really say who was the driver... but I expect it's a little bit of everybody. PRBO and Audubon have been talking to John B. and [the rice growers] for a really long time, so who gets owner- 
ship or credit I don't really know, but I suspect it's everybody.

Evidence for shared ownership extended beyond the project initiation phase, as rice growers made key decisions at many different points in the collaborative research process even as the conservation professionals were guiding the research. For example, according to interviewees in both groups, rice growers made the decisions about which types of practices they wanted to trial on their fields, where those trials could happen, and for how long they would go on. While the rice growers did not participate directly in monitoring birds on their rice fields, they helped to analyze which practices would be feasible on a larger scale, providing feedback to the conservation professionals during the workshop and other informal conversations about how the practices affected their management routines and overall costs of operation. In interviews, several rice growers also commented on the fact that the suite of practices monitored for bird response included a practice that many of them had developed and experimented on informally in their fields previously: widening levees for nesting. Although not a priority for the conservation community because it didn't target migrating shorebirds, the growers nevertheless insisted on including this practice in the experimental trials because it was an easy, cost-effective way to increase habitat on their farms.

We also found evidence of a lack of shared ownership in some parts of the process. Despite not participating in the formal data collection for monitoring the birds, rice growers reported their own informal observations of birds they were seeing on their farms in response to the different management practices. Some rice growers expressed frustration that the monitoring schedule wasn't adequately capturing the bird response they were seeing. They also reported frustration that the conservation professionals didn't modify their monitoring plans based on their feedback. Ron from Colusa explained:

The other interesting thing I've observed in this process is, I start my flooding and sometimes it's a month before they start monitoring. And I've talked to Lindsay [PRBO biologist] and I say, Lindsay, you're missing most of what happens! ... So none of that data ever gets taken because they're not here and then as the acreage expands, the birds spread out so the numbers are less.

Ron's description above was echoed by other growers who described similar instances of exclusion from the decisionmaking process about research activities and monitoring schedules. Conservation professionals indicated that funding and staffing constraints limited their ability to include additional monitoring and shift their schedules according to grower feedback.

While all but two growers agreed that they didn't have time to participate in the monitoring activities themselves, most indicated significant interest in the monitoring data and methods, and desired more frequent updates about the monitoring results than a once per year workshop. At the same time, several growers said they recognized the researchers' time constraints and didn't expect that they would have completely analyzed data sets to share each month. However, studies of collaborative and participatory research projects consistently report the importance of regular communication and sharing results across researchers and community partners (Shirk et al. 2012). For the collaborating rice growers, their sense of ownership and connection to the process might have been strengthened if the conservation professionals provided more frequent brief anecdotal updates about the research, as well as more regular and organized opportunities for the rice farmers to share their own field observations and suggestions.

\section{Building trust}

Even though rice growers began with the explicit goal of finding alignment with environmental interests, building trust across the two groups was a prominent focus for efforts by both groups throughout the collaborative process. Like establishing mutually beneficial goals and shared ownership, building trust is another important process that facilitates learning and collaboration across community boundaries (Fernández-Giménez et al. 2008). The key features of trustbuilding in the Rice and Birds project that emerged in the data and are supported in the literature included: spending time together (Berkes 2009), using brokers (Wenger 1998), and establishing legitimacy (Carr and Wilkinson 2005).

One key feature of the project that seemed to provide opportunities for building trust between the rice and conservation communities was regular and sustained interaction on a formal and informal basis. In interviews, the conservation professionals explained that there was a noticeable progression of engagement on the part of the growers. While at the first meeting in 2009, conservation professionals described the rice growers as "guarded" and keeping "their cards close to their chest," by the second workshop which we observed, growers more actively and enthusiastically participated in the dialogue. In general, the conservation professionals attributed this increasing participation to growers' changing perceptions about, and trust in, the conservation community. Establishing a legitimate role as true partners instead of adversaries was key to this process; for example, Karen from PRBO described what she imagined growers saying to themselves, 
You know, these guys [the conservationists] seem legitimate, they seem like they're not out there to tell us we're managing our land poorly or being bad stewards, these guys actually seem to want to work with us and respect what we're doing and want to just see if there are other things we can do.

Her comment, whether accurate or not to growers' perspectives, reflects her understanding that building trust and mutual respect were key to this work. In interviews, all conservation professionals credited the growing trust to spending time together and building personal relationships. Andy from Audubon had a typical response to the question of how trust was built between the two groups:

Just becoming more familiar with each other. Talking more, meeting more, going out to lunch, seeing each other out in the fields. Just - it's with any relationship really - at first you can be friendly, but you're not necessarily going to be trusting and all that. But as you start to talk to people more, we provided them with summaries of some of the surveys we did, things like that.... I think naturally and justifiably a lot of farming groups are probably, 'These guys want to shut us down'. Not everyone, but some of them probably feel that way. And sometimes it's probably justified...so I think there was a little bit of that at first. But ... as things progress, and we got to know them and they got to know us, now we have a lot of people on board, and it was really interesting to see that progression.

Another key feature of this case that contributed to trustbuilding between rice growers and conservation professionals was the presence of brokers. Brokers are the individuals who encounter discontinuities at the boundaries between different groups and work to build bridges (Akkerman and Bakker 2011). The key role of brokers was illustrated, for example, when interviewees from both communities stressed that John B., the environmental affairs manager of the CRC since 2001, was instrumental in linking the rice and conservation groups. With a background in environmental science and management, John B. had background, reputation, and experience in both the rice and the conservation fields and brought a deep appreciation for and commitment to aligning environmental and industry interests. Other important brokers within the rice community included: Ron, a grower in Colusa with a $\mathrm{PhD}$ in environmental physiology and a love of birds who had been a strong advocate of on-farm conservation for decades; and Jim, a grower-farm manager in Colusa who oversaw conservation planning and habitat restoration for several large, absentee landowners, totaling thousands of acres in the Sacramento Valley. Several other growers cited these growers, as well as John B., for encouraging their involvement in the Rice and Birds project. As legitimate members of the rice grower community, these brokers also had connections to conservation professionals and as such, were able to facilitate dialogue and encourage collaboration between the two groups (Wenger 1998; Cash et al. 2003).

\section{Integrating knowledge}

The factors that facilitate collaboration and learning discussed previously- mutually beneficial goals, shared ownership of process and building trust- all set the stage for open communication and knowledge sharing between the grower and conservation communities. We refer to this process as integrating knowledge because the goal of the Rice and Birds project was not to transfer information between the conservation and grower communities, but to combine and integrate expertise to generate new forms of practice and knowledge about managing agricultural landscapes for birds. We identified two elements of integrating knowledge described in the literature that, in some instances, led to open, equitable dialogue: the similarity of epistemological frameworks (Carr and Hazell 2006) and facilitation techniques (Reed 2008).

Similar epistemological frameworks While epistemological divides and differences between traditional ecological knowledge and scientific knowledge can erect formidable boundaries that complicate collaborative research in many settings (Berkes et al. 2000; Fortmann 2008; Reid and Nikel 2008), both of the communities in this case were grounded in conventional scientific practice and had faith in science as a legitimizing process, as evidenced in the outreach documents and comments during interviews from both groups. Scientific research played a large role in informing farming practice for the rice growers; growers relied on the research conducted both through the university and, in the case of rice, a specialized research center, to generate new varieties, new technologies and new ways of coping with regulation.

Growers and conservation professionals also described in interviews and at the workshop a shared reliance on experimentation to understand their practice and the complex agroecosystems they worked in. Numerous growers cited their reliance on continual experimentation and adaptation, for example, Robert saying:

I think being part of the "Wild West" makes people much more adaptive. I think there's something to be said that agriculture is probably the most highly regulated industry in the world in CA, and yet we're probably the most successful. Now why is that? I mean you've got to adapt.

This comment reflects a frequent framing from growers that adaptation comes through experimentation, and they 
characterized this as a form of trial and error on farms. Noted Sam, a grower from Yuba:

Our mode is that you adapt or you don't survive. So when I say there's a lot of smart people [in farming], it's true because if you're not thinking ahead, ... if you're not doing your own experimentation on your farm every day, if you're not constantly thinking about that and looking ahead you're not in business.

While the on-farm experimentation that Sam described above was likely less systematic than scientific research trials or laboratory experiments, agricultural systems are much more complex, and more akin to the dynamic natural systems with multiple, uncontrollable variables that ecologists and conservationists work in (Carr and Hazell 2006). So, while the growers and conservation professionals came to the project with distinct bodies of knowledge, they shared a fundamental scientific epistemology based on experimentation and observation. This shared understanding of, and faith in, the adaptive experimentation process set the stage for integrating knowledge between the two groups.

Despite the similarities in epistemological framework and practice of adaptation and experimentation that characterizes both agricultural work and applied conservation, some growers expressed skepticism about scientific knowledge produced in academia or government institutions. For example, Sam, a grower in Yuba stressed the importance of the tacit knowledge that comes from participating in practice, as opposed to more academic "book learning," but recognizing that both have a role to play:

You go to a wildlife refuge and you look at these guys and they try to design what they think is the perfect waterfowl habitat. And it's all screwed up, I think. I got more ducks than they do - and I hunt here. So, you know, I don't have a PhD in biology either... but as a wetland manager I think I know a few things.... It's just the difference between anecdotal and experience and what you read in the handbook. So I think there's an opportunity for us both to learn.

Facilitation Although rice growers were generally comfortable communicating in the language of science, we observed the conservation professionals used various facilitation techniques to elicit growers' participation and knowledge sharing at the workshop, acknowledging that the power differential between expert scientific knowledge and applied knowledge held by growers could create obstacles to equitable and open dialogue (Berkes et al. 2000). At one workshop, conservation professionals gave a presentation (after an introduction by a grower) about the importance of agricultural habitats as well as the needs of the birds that still weren't being met by those habitats. After explaining each practice in the presentation and answering any clarifying questions, the growers and other participants were invited to circulate around the room and write their thoughts about the potential benefits and challenges of each practice on large sheets of paper hung on the walls. At each station, small groups of growers and others spontaneously formed to discuss the practices; most growers were not shy about writing their thoughts on the paper. This forum had the effect of ensuring that the conversation was not dominated by one vocal group of people and that those less comfortable speaking in public had an opportunity to voice their concerns and share their opinion. After about an hour of circulating, the entire group walked around the room and discussed each practice in turn, providing yet another opportunity for participants to share thoughts and come to a consensus about the most promising practices to try in terms of meeting needs of both growers and birds.

\section{Institutional alignment}

The final element of the boundary crossing process as described by Wenger (1998) relates to establishing linkages with networks beyond the grower and conservation communities. Creating cross-scale linkages with other networks and institutions is a critical part of maintaining a community's relevance and significance within a larger social system (Wenger, 1998). Others in the natural resource management field note the importance of cross-scale linkages and networks for promoting resilience in social-ecological systems (Colding et al. 2000; Olsson et al. 2004). In interviews and during workshops, participants from both groups reported that it was very important that the collaborative research and conservation work they were doing as part of the Rice and Birds project eventually be formally recognized and acknowledged via government compensation or through market-based rewards.

Although initially the project emphasized practices that could be implemented easily at very low cost, the participants recognized that shifting practice in the agricultural communities on a large scale would take more than a supportive connection with the conservation community or a favorable word from the conservation-minded growers. Since the conservation professionals didn't have the power to pay growers to flood their fields in the fall, they invited representatives from other agencies and networks (NRCS, U.S. Fish and Wildlife Service, local resource conservation districts) who did have the ability to influence incentive policy, to participate in the process. Coordinating with government agencies was a potential risk for partners in terms of establishing trust and legitimacy with the broader rice grower community. Even though growers, during interviews and workshops, emphasized the need for compensation for any financial losses they would suffer as a result of new, 
bird-friendly practices, they all expressed frustration with burdensome and expensive government regulations. Several growers warned that even if compensation for conservation were provided, there would still be those who refused to cooperate because they didn't like to be involved in government programs - period. In addition to wanting to keep a wide berth from potential agency regulation, other growers would be intimidated by what was sure to be a long and complicated process of filling out forms and documenting their practices.

Despite the risk of alienating some growers, the conservation professionals opted to invite government and agency participation because of the potential benefits that would come from coordinating with institutions and networks at a larger scale. While the conservation professionals did not guarantee that payments would become a reality, they made it clear at the outset of each workshop that their intention was to develop practices that would be considered for NRCS funding to recognize the risk and cost of participation. The conservation professionals also stressed that their collaboration on the Rice and Birds project, and the resultant linkages with government agencies that would result, could further help to stem the tide of environmental legislation and regulation that growers feared; by working proactively to preserve habitat of key species, growers could help to keep those birds off the Endangered Species List and thereby avoid regulations associated with the Endangered Species Act.

\section{Learning outcomes of boundary work: knowledge, skills and identity related to practice}

We found evidence of learning by most participants in these boundary crossing experiences, including through the practice of collaborative, adaptive experimentation exemplified in the Rice and Birds Project. This evidence surfaced in the ways that each group, and the individuals within the group, appropriated and created new concepts, ideas, tools, practices, and identities from and with other communities (Table 4). In some instances, we identify and examine missed opportunities for learning during the project.

\section{New knowledge and understanding}

Rice Growers All the rice growers interviewed reported that they understood more about the needs of shorebirds as a result of participating in the collaboration, adding nuance and details to what they already knew. For example, whereas many growers were already familiar with ducks and other waterfowl because of their interest in hunting, the majority did not know about shorebirds or their use of different water depths. Jeff, a rice grower from Yolo, described learning about shorebirds at the first workshop:

I think that helped us as rice growers to understand what they're doing [the birds], why they're here, their migration route, why these birds like this type of water depth. Not everything suits one, one size doesn't fit all I guess.

In interviews, growers also succinctly described their new understanding of the ways in which the different management practices they were testing on their farms offered improved habitat for shorebirds, such as providing shallow water, during critical migration times.

Even though the participating growers like Jeff learned that shorebirds had different needs from waterfowl, several growers lamented that they still were not able to identify the shorebirds in their fields; they wanted this practical field knowledge as well as the ecological knowledge they were gaining. Ron, a rice grower in Colusa and an avid wildlife photographer, described how growers needed an accessible guide to the area shorebirds. Further, even though the collaborative research focus was on migratory shorebird habitat, several growers expressed interest in learning about the needs and migration patterns of other birds as well, in

Table 4 Learning outcomes as a result of boundary work by rice growers and conservation professionals

\begin{tabular}{|c|c|c|}
\hline & Rice growers & Conservation professionals \\
\hline New knowledge & $\begin{array}{l}\text { Enhanced knowledge of habitat needs of shorebirds, and } \\
\text { ways management practices affected habitat }\end{array}$ & $\begin{array}{l}\text { Gained understanding of farming practices, as well as specific } \\
\text { challenges growers face in considering new management } \\
\text { practices such as financial constraints }\end{array}$ \\
\hline New practices & $\begin{array}{l}\text { Identified, evaluated, and committed to rice farming prac- } \\
\text { tices that conservation professionals said would substan- } \\
\text { tially benefit waterbirds, including flooding fields in at } \\
\text { strategic times to create habitat, creating nesting "islands," } \\
\text { and staggering water drawdown to maintain habitat for } \\
\text { longer durations }\end{array}$ & $\begin{array}{l}\text { Took up new collaboration practices and approaches to work- } \\
\text { ing with agricultural interests and stakeholders; Moved from } \\
\text { conservation strategy of trying to identify wildlife friendly } \\
\text { farming practices for the entire Central Valley Region to } \\
\text { targeting practices for specific micro-regions within the } \\
\text { Sacramento Valley }\end{array}$ \\
\hline Shifting Identities & $\begin{array}{l}\text { Further identified with conservation and environmental } \\
\text { communities, and bolstered perceived identity as "environ- } \\
\text { mentally friendly" }\end{array}$ & $\begin{array}{l}\text { Shifted what it means to be a conservationist with regards to } \\
\text { collaborating with growers and willingness to work with } \\
\text { agricultural interests, but also struggled to maintain original } \\
\text { conservation identity }\end{array}$ \\
\hline
\end{tabular}


order to modify their practices to accommodate an even larger number of species. Jim, a rice grower and farm manager in Colusa, didn't think growers involved in the project knew enough about the shorebirds they were trying to help: "I mean, I'm interested [in the birds] and I'm not [wellinformed] at all. You see a tern and the rest are just white." He attributed this to growers' lack of participation in the monitoring effort, saying,

At the end of the day, they're out there because they like to be out there. And if you tap into that...you want to tap that. At the end of the day it's all going to be maintained by the people that are out there. So you have to get that buy-in at some point.

This indicates that the growers participating in the project had a sincere interest in learning more detailed information about the birds, and that the conservation community missed opportunities to engage and capitalize on that curiosity, perhaps through more collaborative monitoring of the bird species. Perhaps most significantly, the growers commented that more in depth knowledge about birds would enable them to strategize ways to modify habitats for other birds, beyond the shorebirds emphasized in the Rice and Birds project. Although these potential next steps were outside the scope of this study, we see how the objectives of the initial collaboration across grower and conservation boundaries could lead to successive problem solving and a sustained boundary practice (Olsson et al. 2004; Berkes 2009), and in fact, citizen science and collaborative monitoring efforts did ultimately occur in this region in the years following these workshops.
Conservation professionals Just as the grower communities gained new understandings about the birds from the conservation professionals (but wished for more), the conservation professionals gained a new appreciation for and understanding of farming practice. In interviews with conservation professionals, all echoed the sentiment of Andy from Audubon who reported that, "We [the conservation community] learned far, far more from the growers than they learned from us." Perhaps most importantly, the conservation professionals reported gaining an appreciation for the financial constraints and risks that go with farming and that make it challenging for growers to participate in habitat enhancement programs even if they seem to be low-cost.

In addition to understanding the importance of financial constraints and risk, conservation professionals learned about a host of other challenges and constraints that rice growers faced in implementing new management practices to benefit migratory birds. In fact, MBCP presented a list of the key lessons learned by the MBCP during the discussions and dialogue that took place at the workshop and reported them in the Workshop Proceedings (MBCP, 2010) (Table 5). These published lessons reveal that the conservation groups learned about both the challenges growers faced and the opportunities growers saw for enhancing habitat in their agricultural fields. The summaries detail very specific constraints and limitations, such as mosquito abatement schedules and regional differences in water availability, that could have important implications for the collaborative research process and the practice of the MBCP and larger conservation community in general.

Table 5 Summary of lessons learned from the Rice and Birds workshop (MBCP, 2010)

\begin{tabular}{|c|c|}
\hline Lessons & Examples \\
\hline Regional differences & $\begin{array}{l}\text { Water delivery constraints, soils, and other factors differ greatly among rice farms } \\
\text { by region }\end{array}$ \\
\hline Public perception & Future of rice as a surrogate wetland habitat depends on the public's understanding of its importance \\
\hline Adapting to changing conditions & $\begin{array}{l}\text { Growers need flexibility to manage practices according to changes in conditions. As an example, rainfall } \\
\text { variation may influence growers' ability to implement practices such as variable drawdown }\end{array}$ \\
\hline Importance of hunting and waterbirds & $\begin{array}{l}\text { Importance of hunting and waterbirds. Hunters are a valuable ally in rice field management; their inter- } \\
\text { ests and the negative consequences of any practices need to be addressed }\end{array}$ \\
\hline Cost & All practices have extra costs. How can we compensate growers? \\
\hline Communicating and seeing results & $\begin{array}{l}\text { Growers need to see real benefits to birds in order to try different practices. Communicating the birds' } \\
\text { needs and the results of monitoring and experiments is essential }\end{array}$ \\
\hline Nutrient concerns & $\begin{array}{l}\text { Too much water movement and repeated flooding-drawdown-flooding are problematic because of nitro- } \\
\text { gen loss }\end{array}$ \\
\hline Water district issues & Water district closures restrict flexibility in maintaining optimal water depths \\
\hline Flooding practices & $\begin{array}{l}\text { Sustained flooding practices are more practical than pulse flooding practices. Staggering water box board } \\
\text { heights may cost less than pulse flooding or variable drawdown }\end{array}$ \\
\hline Mosquito abatement issues & It is more expensive to flood before October 1 st due to mosquito abatement programs \\
\hline
\end{tabular}




\section{New practices}

In addition to new knowledge and understanding, new practices are important outcomes for learning within and across communities in a social theory of learning (Wenger 1998). The entire purpose of the Rice and Birds project was to generate new forms of agricultural practice that would benefit birds through a process of collaborative, adaptive experimentation and monitoring, and both rice growers and conservation professionals described ways they collectively and individually learned and gained new practices.

Rice growers The workshops seem to have been an important vehicle for rice growers to identify, and potentially adopt, new practices as an outcome of the collaborative research process. Rice growers and conservation professionals identified several new practices during the second Rice Grower Workshop that would be selected for adaptive experimentation and monitoring. At the conclusion of the workshop, workshop participants collaboratively ranked the six candidate practices in terms of which would be most beneficial to waterbirds and feasible to implement for growers. Table 6 illustrates the priority ranking of each practice among participants.

Based on these rankings, the group identified four major practices to be field tested and implemented over the following 2-3 years. The practices represent the integration of rice grower knowledge and expertise about agricultural practice coupled with the conservation professionals' understanding about the needs of various bird species. The shared understanding of what these practices consist of, and their potential significance for the birds, illustrates a growing overlap between the conservation and rice grower communities and the development of a shared repertoire of techniques and language indicative of a boundary practice. Ultimately, the top four practices were chosen as the basis for the NRCS Waterbird Habitat Enhancement Program in California's Central Valley, beginning as a pilot program in two counties in 2011 and spreading to eight counties in 2012.
Conservation professionals Because the collaborative project focused on defining new agricultural practices, it's less evident how the boundary crossing encounters influenced the conservation professional practice. However, the conservation community gained competence and new practices in terms of collaboration skills - collaborating with agricultural groups and finding ways to redefine conservation in the context of working landscapes. Collaborating with agricultural interests is evidence of a departure from conservation practice in the past, which was focused on land preservation. For example, Andy from Audubon remarked:

I can't speak too much to the politics of Audubon 20 years ago, but a lot of the effort was, "let's buy land and restore it." And that's still a thrust and it's important, but you can't buy all the land. There's not enough money and people still need to eat. You need farmland... So, both are important, the restoration is important but also the farm-scaping and working on working lands to make them better for wildlife are important.

Andy's comments illustrate the pragmatic approach that the MBCP took with respect to collaborating and compromising with agricultural interests in order to have an impact on conservation in California. The conservation groups also developed terms to talk about this new approach to combining conservation and agriculture: "wildlife-friendly farming" and "compatible agriculture." While the MBCP project was not solely responsible for this shift towards practical, collaborative conservation, the conservation professionals involved in the project were at the forefront of this effort. This is reflective of changes in conservation practice that are happening in the broader field in which conservationists are increasingly recognizing the need for habitat conservation on working landscapes to protect biodiversity (Kremen and Merenlender 2018).

Evidence for changes in practice could also be found at a much smaller scale within the MBCP. Numerous conservation professionals described how their newfound understanding of the diverse and complex constraints growers faced when implementing "wildlife friendly" practices (especially in the rice fields) led to a shift in strategy from developing

Table 6 Priority ranking of candidate rice management practices to benefit waterbirds

\begin{tabular}{lll}
\hline Ranking & Practice & Description \\
\hline 1 & September flooding & Flood available fields to create habitat for fall migrant birds \\
2 & Breeding "islands" & Increase nesting habitat sites by installing islands and widening berms \\
3 & Variable drawdown & $\begin{array}{c}\text { Stagger field drainage by delaying drainage of flooded fields to provide a range of } \\
\text { water depths later into winter }\end{array}$ \\
4 & Boards in after harvest & Passive capture of rainwater on fields by replacing boards in water control structures \\
5 & Late winter flooding & Flooding when habitat needed but not necessary for rice cultivation \\
6 & Winter flushing & Flood and drain fields \\
\hline
\end{tabular}


practices and outreach for the entire Central Valley region to targeting practices for specific micro-regions within the Sacramento Valley. As a result of what they learned, the MBCP members began creating a region-wide map of water management districts, mosquito abatement districts, and estimates about where the birds would be during different times of the year in order to help drive the direction of future research and implementation.

\section{Shifting identities}

In addition to new knowledge and practices, evidence for learning can also be found in the ways that individual and community identities change because of participation in a shared practice (Wenger 1998). Shifts in identity at the individual level are evident in the ways that participants develop competence within a practice, participate differently within a practice by taking on new roles, and negotiate membership and belonging with the various communities to which they belong (Wenger 1998). At the collective level, changes in identity can be found in changing forms of practice, new ways of defining competence and membership, and new narratives and repertoires (Wenger 1998). While identity shifts can often be subtle, take time to develop, and be difficult to attribute to a particular instance (Thomashow 1996; Handley et al. 2006), interview, workshop and documentary evidence points to ways in which the Rice and Birds project contributed to identity shifts among participants and their respective communities.

Rice Growers Participation in the project represented an opportunity for rice growers to further identify themselves with conservation and environmental communities. Previously, the rice growing community sought ways to identify itself as "environmentally friendly" since air quality regulations forced growers to stop burning rice straw in the early 1990s. The collaboration with the MBCP offered an opportunity for growers to bolster this image, or perceived identity. Several growers mentioned that they were no longer in the business of growing rice, but in "managing wetlands," perhaps reflecting a development of their own ecological identity as Thomashow (1996) terms the cultivation of a reflective environmental perspective. Jim, a grower in Colusa, said half-jokingly: "We don't even call them rice fields anymore, we only call them 'surrogate wetlands' now... They only grow the rice in the summer just for something to do in between. Our real crop now is habitat." The collaboration with the MBCP presented an opportunity for the rice growing community to build their perceived identity as an environmentally friendly industry and bolster their reputation with the public.

However, whether this was a true identity shift for growers, or just an effort at shaping public perception, is unclear. Jim, farm manager and grower in Colusa, noted the importance of public recognition, and was working to set up a labeling scheme for rice growers. While labeling efforts are less common in commodity crops like rice that are sold wholesale, without direct connection to the consumer, he was confident that certifying and labeling certain rice growers as "bird-friendly" would go a long way to convince growers about the value of ecological practices, while also boosting awareness of growers' environmental contributions in the public.

Conservation professionals Conservation professionals meanwhile developed an identity shift in what it means to be a conservationist: that being a conservation professional means collaborating with growers and demonstrating a willingness and an ability to work with agricultural interests. Despite some skepticism or downright antagonism about collaborating with agricultural interests within the larger conservation community, the boundary work of the Rice and Birds Project demonstrated these conservation professionals' willingness to compromise with agricultural communities.

At the same time, we found evidence that maintaining their identity as conservationists amidst the collaboration was a struggle for some of these professionals. Karen from TNC described the process:

It was a little bit of a struggle at first to figure out the best way to represent our work. Because I feel like you really want to hit that sweet spot where you're emphasizing where you have mutual interests and where there's mutual benefit but at the same time you don't want to sort of - we are a conservation group we are a green group. So you can't misrepresent your interests. No, we're not going to go tattling to the agencies if you have something bad going on - but at the same time, our interest IS in restoring habitat and clean water and clean air.

In this comment, Karen revealed how it was difficult for members of the MBCP to reconcile their identity as conservationists with the need to coordinate and compromise with growers who at times shared different values and motives.

\section{Discussion}

We were hoping they would just tell us what to do! It would have made things a lot easier if [Audubon] had just given us an environmental checklist and said, 'You guys just do these 6 things and you'll get a clean bill of health from us and we'll write nice articles'.

- Sam, Yuba County Rice Grower 
According to Sam, it would have been a lot less effort, on everyone's part, if the conservation professionals were able to hand over a list of practices growers could implement to benefit birds. However, adoption of conservation practices in agricultural settings is not as straightforward a process as Sam's quote indicates, as there are a myriad of factors that influence implementation of these types of practices (Nowak 1987; Garbach and Long 2017). Additionally, the conservation professionals could not do what Sam suggested, because they did not know what those practices were in the unique context of working rice farms in the Sacramento Valley. To design a strategy for managing rice fields to benefit migratory birds, the growers and conservation professionals needed to learn from one another. Growers needed to learn about the habitat needs for target bird species. Conservation professionals needed to learn about rice production practices, and growers' constraints and resources. And even then, exchanging information would not have been enough; both groups still had something to learn about the birds themselves in terms of how they ultimately responded to the new practices.

The Rice and Birds collaborative research project grew out of this need for growers and conservation professionals to learn together how to enhance and create bird habitat in rice fields. Drawing on theoretical perspectives that understand learning as a social activity as well as concepts of boundaries and boundary work, we sought to understand how and what each of these communities learned by participating in this shared practice of adaptive experimentation.

We found that the collaborative research process functioned as a form of boundary work, bridging barriers between the growers and conservation professionals, and helping to facilitate learning and collaboration. Building on previous research, we identified and provided evidence of the key factors supporting the boundary work in this case including: mutually beneficial goals, shared ownership of process, trust building, integrating knowledge, and alignment with networks and communities of different scales (as summarized earlier in Table 3). Our study suggests that attending to these factors in designing collaborative research initiatives might maximize opportunities for boundary work in which individuals from different communities can learn from each other and result in outcomes like new knowledge, new practices, and shifting identities (Fig. 1).

Overall, conservation professionals reported significantly more gains in knowledge and understanding during this collaboration than the growers themselves. In many ways, this imbalance represents a change from traditional extension and technology transfer models that privilege scientific research and information and tend to ignore local, experiential forms of knowledge (Pretty and Chambers 2003). And yet, participatory forms of research sometimes run the risk of using knowledge from non-scientist participants without adequately providing something in return (Hickey and Mohan 2004). In the case of the Rice and Birds Project, conservation professionals made a great effort to learn from growers and include their ideas and expertise in the research process while respecting their time constraints, but they may have underestimated the growers' desire to gain more expertise about birds and bird ecology in return. Numerous growers mentioned that they would have liked the conservation community to provide them with a guide to help them learn about the birds in their fields. This boundary object, a documented example of knowledge sharing across communities (Wenger 1998; Akkerman and Bakker 2011), was in fact created by bird biologists at Point Blue and published on the CRC website in 2011, after this study ended (PRBO Conservation Science 2011).

Integrating knowledge across the conservation and grower communities in order to inform the research process was in some part dependent on the grower and conservation groups sharing a common epistemological framework (Carr and Wilkinson 2005; Carr and Hazell 2006) and having an opportunity to dialogue in a respectful, open way (Habermas 1985; Mezirow 1991; Vella 2002). Wenger (1998) also noted the importance of sharing common knowledge frameworks and open communication to facilitate learning within communities. Epistemology can be considered a part of a community's shared repertoire, while dialogue is a form of mutual engagement. In the Rice and Birds case, in which scientific experimentation formed the basis of a shared epistemological framework, these factors also appeared to
Fig. 1 Model of how key factors shape learning processes and outcomes of collaborative research

\section{Factors}

- Mutually beneficial goals

- Shared ownership of process

- Building trust

- Integrating knowledge

- Institutional alignment
Catalyst: Collaborative research

Process: Learning as 'Boundary Work'

Outcomes: New knowledge, new practices, and shifting identities 
facilitate learning and knowledge sharing between communities, and to further establish the shared repertoire and forms of mutual engagement that characterized the developing boundary practice between the grower and conservation communities. Even in cases where epistemological frameworks between different groups is quite divergent such as between foresters and harvesters in Washington, USA (Ballard and Belsky 2010) or foresters, nature reserve staff, and villagers in Yunnan, China (Van Rijsoort and Jinfeng 2005), collaborative research can still provide a forum for learning and boundary work should there be careful attention to designing processes that support the meaningful participation of all involved. However, it is important to note that collaborative processes-regardless of the similarities in epistemological frameworks between groups-will not inherently result in learning (Reed et al. 2010), and there are a number of additional factors that facilitate or hinder learning such as power, status, and rank (Suškevičs et al. 2019).

The sustained nature of the boundary work and the relationships and trust that developed as a result of the shared endeavor suggest that the collaborative research effort of the Rice and Birds project on the whole became a boundary practice (Wenger 1998). This boundary practice has since evolved into the BirdReturns program, incorporating economic incentives with the use of citizen science data from eBird, which has facilitated the ability of the grower and conservation groups to identify, manage and adapt to the challenge of bird habitat conservation on a landscape-scale. Maintaining connections between stakeholder communities through shared practice, in this case collaborative research, can have important implications for collaborative management. Co-management cases that develop through time and rely on learning as participation in shared practice can lead to more effective cooperation, each round of problem-solving leading to another (Berkes 2009). In the case of the Rice and Birds project, rice growers reported interest in learning about and improving habitat for birds beyond those emphasized in the current research effort. The development of the BirdReturns and integration of eBird offer evidence that conservation professionals took this opportunity to encourage and build upon this common interest and shared practice, acting as resources and facilitators for growers as they sought to expand and adapt their practice to include new forms of habitat improvement.

Several MBCP conservation professionals cautioned that despite the importance of building relationships with growers and tweaking agricultural practices on the ground, at the end of the day, conservation strategies that rely on voluntary participation are subject to the decisions of individual growers. So, a combination of strategies, including land preservation and shifting management practices on the ground to benefit wildlife, need to happen in order to be effective and to mitigate risk. This study also indicates that in the case of working landscapes, collaborating with established agricultural industries with strong leadership structures, like the $\mathrm{CRC}$, can be an effective means of promoting conservation practices.

\section{Conclusion}

Because of its critical role in fostering conservation, learning has become a normative goal in contexts like the Rice and Birds case (Berkes 2009). By bringing theoretical perspectives of learning as a social practice together with insights from research on conservation and natural resource management, this study contributed to an understanding of how learning happens between stakeholder groups through the practice of collaborative research. Insights about the factors that supported and facilitated learning across grower and conservation community boundaries could provide important guidelines for practitioners who seek to promote collective conservation action and learning among stakeholder groups in similar contexts. Building relationships, boundary practices, and shared histories of learning and collaboration between grower and conservation communities seem to be one strategy, among many, needed to protect wildlife in our increasingly human-dominated landscape and to meet the uncertain environmental challenges that lie ahead.

Acknowledgements We would like to thank the rice growers and conservation professionals who were so generous with their time and thinking. We also acknowledge the Hellman Foundation for their support of this project through the Hellman Fellows program at the University of California, Davis.

Open Access This article is licensed under a Creative Commons Attribution 4.0 International License, which permits use, sharing, adaptation, distribution and reproduction in any medium or format, as long as you give appropriate credit to the original author(s) and the source, provide a link to the Creative Commons licence, and indicate if changes were made. The images or other third party material in this article are included in the article's Creative Commons licence, unless indicated otherwise in a credit line to the material. If material is not included in the article's Creative Commons licence and your intended use is not permitted by statutory regulation or exceeds the permitted use, you will need to obtain permission directly from the copyright holder. To view a copy of this licence, visit http://creativecommons.org/licenses/by/4.0/.

\section{References}

Akkerman, S.F., and A. Bakker. 2011. Boundary crossing and boundary objects. Review of Educational Research 81 (2): 132-169.

Armitage, D.R., F. Berkes, and N. Doubleday. 2007. Adaptive co-management: Collaboration, learning and multi-level governance. Vancouver, BC: University of British Columbia Press.

Armitage, D.R., R. Plummer, F. Berkes, R.I. Arthur, A.T. Charles, I.J. Davidson-Hunt, and E.K. Wollenberg. 2008. Adaptive 
co-management for social-ecological complexity. Frontiers in Ecology and the Environment 7 (2): 95-102.

Audubon. 2012. Audubon California Conservation Efforts 2012. Retrieved from http://ca.audubon.org/conservation-efforts

Ballard, H.L., and J.M. Belsky. 2010. Participatory action research and environmental learning: Implications for resilient forests and communities. Environmental Education Research 16 (5-6): 611-627.

Ballard, H. L., M. E. Fernández-Giménez, and V. E. Sturtevant. 2008. Integration of local ecological knowledge and conventional science: a study of seven community-based forestry organizations in the USA. Ecology and Society 13(2).

Berkes, F. 2009. Evolution of co-management: Role of knowledge generation, bridging organizations and social learning. Journal of Environmental Management 90 (5): 1692-1702.

Berkes, F., and N.J. Turner. 2006. Knowledge, learning and the evolution of conservation practice for social-ecological system resilience. Human Ecology 34 (4): 479-494.

Berkes, F., J. Colding, and C. Folke. 2000. Rediscovery of traditional ecological knowledge as adaptive management. Ecological Applications 10 (5): 1251-1262.

BirdReturns. 2020. Program Overview. The Nature Conservancy. https://birdreturns.org/home-page/about/about/

California Ricelands Waterbird Foundation. 2018. BirdReturns enables growers to help birds. https://calricewaterbirds.org/california-birdr eturns/

Carr, A., and D. Hazell. 2006. Talking frogs: The role of communication in ecological research on private land. Biodiversity and Conservation 15 (10): 3177-3191.

Carr, A., and R. Wilkinson. 2005. Beyond participation: Boundary organizations as a new space for farmers and scientists to interact. Society and Natural Resources 18 (3): 255-265.

Cash, D.W., W.C. Clark, F. Alcock, N.M. Dickson, N. Eckley, D.H. Guston, J. Jäger, and R.B. Mitchell. 2003. Knowledge systems for sustainable development. Proceedings of the National Academy of Sciences 100 (14): 8086-8091.

Cerf, M., D. Gibbon, B. Hubert, R. Ison, J. Jiggins, M. Paine, J. Proost, and N. Röling, eds. 2000. Cow up a tree: Knowing and learning for change in agriculture; case studies from industrialised countries. Paris: INRA.

Clark, W. C., T. P. Tomich, M. van Noordwijk, D. Guston, D. Catacutan, N. M. Dickson, and E. McNie. 2011. Boundary work for sustainable development: Natural resource management at the Consultative Group on International Agricultural Research (CGIAR). Proceedings of the National Academy of Sciences, Early Edition, 8.

Colding, J., F. Berkes, and C. Folke. 2000. Linking social and ecological systems: Management practices and social mechanisms for building resilience. Cambridge: Cambridge University Press.

Central Valley Joint Venture. 2006. Central Valley Joint Venture Implementation Plan - Conserving Bird Habitat. Sacramento, CA.

Daniels, S.E., and G.B. Walker. 2001. Working through environmental conflict: The collaborative learning approach. Westport CT: Praeger Publishers.

Danielsen, F., N. D. Burgess, A. Balmford, P. F. Donald, M. Funder, J. P. G. Jones, and J. Brashares. 2008. Local participation in natural resource monitoring: A characterization of approaches. Conservation Biology 23 (1): 31-42.

Elphick, C.S. 2000. Functional equivalency between rice fields and seminatural wetland habitats. Conservation Biology 14 (1): 181-191.

Elphick, C.S., and L.W. Oring. 1998. Winter management of Californian rice fields for waterbirds. Journal of Applied Ecology 35 (1): 95-108.

Ernst, A. 2019. Review of factors influencing social learning within participatory environmental governance. Ecology and Society 24(1).
Evans, C., E. Abrams, R. Reitsman, K. Roux, L. Salmonsen, and P.P. Marra. 2005. The Neighborhood Nestwatch Program: Participant outcomes of a citizen-science ecological research project. Conservation Biology 19 (3): 589-594.

Fernández-Giménez, M. E., H. L. Ballard, V. E. and Sturtevant. 2008. Adaptive management and social learning in collaborative and community-based monitoring: A study of five community-based forestry organizations in the Western USA. Ecology and Society 13(2).

Fernández-Giménez, M. E., D. J. Augustine, L. M. Porensky, H. Wilmer, J. D. Derner, D. D. Briske, and M. O. Stewardt. 2019. Complexity fosters learning in collaborative adaptive management. Ecology and Society 24(2).

Fisher, D. 1989. Boundary work: a model of the relation between power and knowledge. Knowledge: Creation, Diffusion, Utilization 10: $156-176$.

Folke, C., T. Hahn, P. Olsson, and J. Norberg. 2005. Adaptive governance of social-ecological systems. Annual Review of Environmental Resources 30: 441-473.

Fortmann, L. 2008. Participatory research in conservation and rural livelihoods: Doing science together. Hoboken, NJ: Wiley-Blackwell.

Garbach, K., and R.F. Long. 2017. Determinants of field edge habitat restoration on farms in California's Sacramento Valley. Journal of Environmental Management 189: 134-141.

Glaser, B.G., and A.L. Strauss. 1967. The discovery of grounded theory: Strategies for qualitative research. Rutgers, NJ: Transaction Publishers.

Gerlak, A.K., T. Heikkila, S.L. Smolinski, D. Huitema, and D. Armitage. 2018. Learning our way out of environmental policy problems: A review of the scholarship. Policy Sciences 51 (3): 335-371.

Gerlak, A.K., T. Heikkila, S.L. Smolinski, D. Armitage, D. Huitema, and B. Moore. 2019. It's time to learn about learning: Where should the environmental and natural resource governance field go next? Society and Natural Resources 32 (9): 1056-1094.

Gieryn, T.F. 1983. Boundary-work and the demarcation of science from non-science: Strains and interests in professional ideologies of scientists. American Sociological Review 48 (6): 781-795.

Habermas, J. 1985. The theory of communicative action. Lifeworld and system: A critique of functionalist reason, vol. 2. Boston, MA: Beacon Press.

Handley, K., A. Sturdy, R. Fincham, and T. Clark. 2006. Within and beyond communities of practice: Making sense of learning through participation, identity and practice. Journal of Management Studies 43 (3): 641-653.

Hickey, S., and G. Mohan. 2005. Towards participation as transformation: Critical themes and challenges. Participation from tyranny to transformation?: Exploring new approaches to participation in development, 3-24. London: Zed Books.

Johnson, N.L., A. Lilja, and J.A. Ashby. 2003. Measuring the impact of user participation in agricultural and natural resource management research. Agricultural Systems 78 (2): 287-306.

Knight, A.T., R.M. Cowling, M. Difford, and B.M. Campbell. 2010. Mapping human and social dimensions of conservation opportunity for the scheduling of conservation action on private land. Conservation Biology 24 (5): 1348-1358.

Kremen, C., and A.M. Merenlender. 2018. Landscapes that work for biodiversity and people. Science 362 (6412): eaau6020.

Lamont, M., and V. Molnár. 2002. The study of boundaries in the social sciences. Annual Review of Sociology 28: 167-195.

Lave, J., and E. Wenger. 1991. Situated learning: Legitimate peripheral participation. New York: Cambridge University Press.

Lee, K. 1993. Compass and gyroscope: Integrating science and politics for the environment. Washington, DC: Island Press. 
Leeuwis, C., and R. Pyburn, eds. 2002. Wheelbarrows full of frogs: Social learning in rural resource management. Assen, The Netherlands: Koninklikje van Gorcum.

Lemke, J.L. 2001. Articulating communities: Sociocultural perspectives on science education. Journal of Research in Science Teaching 38 (3): 296-316.

MBCP. 2010. Rice and Waterbird Workshop Summary Report. Proceedings of the 2010 Rice and Waterbird Workshop, Colusa, CA.

MBCP. 2012. 2011 Forage Crops and Migratory Birds Workshops Summary Report. Proceedings of the 2011 Forage Crops and Migratory Birds Workshops: Exploring Challenges and Opportunities to Expanding Migratory Bird Benefits from Forage Production Woodland, CA and Los, Banos, CA.

Merriam, S.B. 1998. Qualitative research and case study applications in education. New York, NY: Wiley.

Mezirow, J. 1991. Transformative dimensions of adult learning. New York, NY: Jossey-Bass.

Muro, M., and P. Jeffrey. 2008. A critical review of the theory and application of social learning in participatory natural resource management processes. Journal of Environmental Planning and Management 51 (3): 325-344.

Nowak, P.J. 1987. The adoption of agricultural conservation technologies: Economic and diffusion explanations. Rural Sociology 52 (2): 208.

Olsson, P., C. Folke, and F. Berkes. 2004. Adaptive comanagement for building resilience in social-ecological systems. Environmental Management 34 (1): 75-90.

Pahl-Wostl, C., and M. Hare. 2004. Processes of social learning in integrated resources management. Journal of Community and Applied Social Psychology 14 (3): 193-206.

Polasky, S., E. Nelson, E. Lonsdorf, P. Fackler, and A. Starfield. 2005. Conserving species in a working landscape: Land use with biological and economic objectives. Ecological Applications 15 (4): $1387-1401$.

PRBO Conservation Science. 2011. Enhancing waterbird habitat in California rice lands: Grower Field Guide. Retrieved from: www. calrice.org/pdf/Grower+field+guide.pdf

Pretty, J., and R. Chambers. 2003. Towards a learning paradigm: new professionalism and institutions for agriculture. In Rethinking sustainability: Power, knowledge, and institutions, ed. J. Harris. Ann Arbor, MI: University of Michigan Press.

Pretty, J., and D. Smith. 2004. Social capital in biodiversity conservation and management. Conservation Biology 18 (3): 631-638.

Raymond, C.M., and G. Brown. 2011. Assessing conservation opportunity on private land: Socio-economic, behavioral, and spatial dimensions. Journal of Environmental Management 92 (10): 2513-2523.

Reed, M.S. 2008. Stakeholder participation for environmental management: A literature review. Biological Conservation 141 (10): 2417-2431.

Reed, M. S., A. C. Evely, G. Cundill, I. Fazey, J. Glass, A. Laing, J. Newig, B. Parrish, C. Prell, C. Raymond, and L. C. Stringer. 2010. What is social learning? Ecology and Society, 15(4).

Reid, A., and J. Nikel. 2008. Differentiating and evaluating conceptions and examples of participation in environment-related learning. In Participation and learning, ed. A. Reid, B.B. Jensen, J. Nikel, and V. Simovska, 32-60. Netherlands: Springer.

Richter, B.D., and K.H. Redford. 1999. The art (and science) of brokering deals between conservation and use. Conservation Biology 13 (6): 1235-1237.

Robinson, C. and T. Wallingford. 2012. Boundary work: Engaging knowledge systems in co-management of feral animals on indigenous lands. Ecology and Society 17(2)

Rodela, R. 2013. The social learning discourse: Trends, themes and interdisciplinary influences in current research. Environmental Science and Policy 25: 157-166.
Röling, N. 2002. Beyond the aggregation of individual preferences. In Wheelbarrows full of frogs: Social learning in rural resource management, ed. C. Leeuwis and R. Pyburn. Koninklijke van Gorcum: Assen, The Netherlands.

Sayer, J., T. Sunderland, J. Ghazoul, J.L. Pfund, D. Sheil, E. Meijaard, M. Venter, A.K. Boedhihartono, M. Day, C. Garcia, C. Van Oosten, and L.E. Buck. 2013. Ten principles for a landscape approach to reconciling agriculture, conservation, and other competing land uses. Proceedings of the National Academy of Sciences 110 (21): 8349-8356.

Shirk, J. L., H. L. Ballard, C. C. Wilderman, T. Phillips, R. Jordan, E. Mccallie, M. Minarchek, B. V. Lewenstein, M. E. Krasny, and R. Bonney. 2012. Public participation in scientific research: A framework for deliberate design. Ecology and Society, 17(2).

Star, S. 2010. This is not a boundary object: Reflections on the origin of a concept. Science, Technology, and Human Values 35 (5): 601-617.

Suškevičs, M., T. Hahn, and R. Rodela. 2019. Process and contextual factors supporting action-oriented learning: A thematic synthesis of empirical literature in natural resource management. Society and Natural Resources 32 (7): 731-750.

Theobald, D.M., and N.T. Hobbs. 2002. A framework for evaluating land use planning alternatives: Protecting biodiversity on private land. Conservation Ecology 6 (1): 5.

Thomashow, M. 1996. Ecological identity: Becoming a reflective environmentalist. Boston, MA: MIT Press.

Van Rijsoort, J., and Z. Jinfeng. 2005. Participatory resource monitoring as a means for promoting social change in Yunnan, China. Biodiversity and Conservation 14 (11): 2543-2573.

Vella, J. 2002. Learning to listen, learning to teach: The power of dialogue in educating adults. New York: Jossey-Bass.

Weiss, R.S. 1995. Learning from strangers: The art and method of qualitative interview studies. New York: Simon and Schuster.

Wenger, E. 1998. Communities of practice: Learning, meaning, and identity. New York: Cambridge University Press.

Wenger, E. 2010. Communities of practice and social learning systems: The career of a concept. In Social learning systems and communities of practice, ed. C. Blackmore, 179-198. London, UK: Springer.

Zurba, M., and F. Berkes. 2014. Caring for country through participatory art: Creating a boundary object for communicating indigenous knowledge and values. Local Environment 19 (8): 821-836.

Zurba, M., K. Maclean, E. Woodward, and D. Islam. 2019. Amplifying Indigenous community participation in place-based research through boundary work. Progress in Human Geography 43 (6): $1020-1043$

Publisher's Note Springer Nature remains neutral with regard to jurisdictional claims in published maps and institutional affiliations.

Erin Hardie Hale is a Project Director at the NH Food Alliance, University of New Hampshire (UNH) Sustainability Institute and a lecturer in the Sustainability Dual Major program at UNH.

Christopher C. Jadallah is a PhD Candidate in Science and Agricultural Education and a National Science Foundation Graduate Research Fellow at the University of California, Davis.

Heidi L. Ballard is a Professor of Environmental Science Education and Founder and Faculty Director of the Center for Community and Citizen Science at the University of California, Davis. 